\title{
Nonoperative treatment for nonperforated appendicitis in children: a systematic review and meta-analysis
}

\author{
Sonia Maita ${ }^{1} \cdot$ Björn Andersson ${ }^{2} \cdot$ Jan F. Svensson ${ }^{2,3} \cdot$ Tomas Wester $^{2,3}$ (D)
}

Accepted: 6 December 2019 / Published online: 14 December 2019

(c) The Author(s) 2019

\begin{abstract}
Acute appendicitis is the most common surgical emergency in children. Nonoperative treatment of nonperforated acute appendicitis in children is an alternative to appendectomy. The purpose of this systematic review and meta-analysis was to determine the outcomes of nonoperative treatment of nonperforated acute appendicitis in children in the literature. Databases were searched to identify abstracts, using predefined search terms. The abstracts were reviewed by two independent reviewers and articles were selected according to inclusion and exclusion criteria. Data were extracted by the two reviewers and analyzed. The literature search yielded 2743 abstracts. Twenty-one articles were selected for analysis. The study design was heterogenous, with only one randomized controlled study. The symptoms resolved in $92 \%$ [95\% CI (88; 96)] of the nonoperatively treated patients. Meta-analysis showed that an additional 16\% (95\% CI 10;22) of patients underwent appendectomy after discharge from initial hospital stay. Complications and length of hospital stay was not different among patients treated with antibiotics compared with those who underwent appendectomy. Nonoperative treatment of nonperforated acute appendicitis children is safe and efficient. There is a lack of large randomized controlled trials to compare outcomes of nonoperative treatment with appendectomy.
\end{abstract}

Keywords Nonoperative treatment $\cdot$ Antibiotics $\cdot$ Appendectomy $\cdot$ Nonperforated $\cdot$ Appendicitis $\cdot$ Children

\section{Introduction}

\section{Rationale}

Appendicitis is the most common indication for emergency surgery in both adults and children worldwide. The estimated lifetime risk is $7-8 \%$ and the peak incidence is in the second decade of life [1,2].

Operative management has been the gold standard of treatment for many years based on the assumption that, left untreated, acute appendicitis would always progress to perforation. This assumption has been questioned and today, there is strong support for spontaneous resolution of

Tomas Wester

tomas.wester@sll.se

1 Pediatric Surgery Unit, Department of Women's and Children's Health, University of Padua, Padua, Italy

2 Department of Pediatric Surgery, Karolinska University Hospital, 17176 Stockholm, Sweden

3 Department of Women's and Children's Health, Karolinska Institutet, Stockholm, Sweden appendicitis [2]. Nonoperative treatment of inflammatory and infectious diseases in the abdomen has been proposed and favored for other conditions like diverticulitis [3]. Nonoperative treatment for acute nonperforated appendicitis has been proven to work well in the short term [4]. No long-term data have been presented.

Despite both open and laparoscopic appendectomy being regarded as low-risk and effective procedures, operative management is associated with risks and complications. The risks are those associated with general anesthesia and surgical complications such as hemorrhage, surgical site infection, injury to surrounding structures, ileus, adhesive small bowel obstruction, the potential need for reoperation or negative appendectomy. Advantages of the initial nonoperative treatment strategy are the avoidance of complications related to surgery and anesthesia, but these risks should be balanced against the risk of complications related to antibiotic treatment and recurrent appendicitis. Apart from balancing the risk of surgery against nonoperative treatment, there may be other reasons for not to undergo surgery. The appendix is a reservoir for bacteria that normally constitute the gut flora, and is needed to recolonize the bowel after bacterial 
infections, e.g. diarrheal disease [5]. A biofilm, adherent colonies of microbes growing within an extracellular matrix, is most prominent in the appendix and decreases progressively to the distal end of the bowel [5]. The vermiform appendix is capable of producing mesenchymal stem cells [6]. Hypothetically, the vermiform appendix is a reservoir for stem cells capable of bowel repair throughout life.

Furthermore, the use of both imaging [7] and biomarkers $[8,9]$ makes it easier to accurately differentiate perforated from nonperforated acute appendicitis and to guide the decision-making.

\section{Objective}

The aim of this study was to systematically review the available evidence of nonoperative treatment of acute nonperforated appendicitis in the pediatric population and to compare the efficacy and safety of nonoperative versus surgical treatment.

\section{Methods}

\section{Protocol and registration}

This systematic review and meta-analysis were conducted according to the Preferred Reporting Items for Systematic Reviews and Meta-analyses (PRISMA) statement.

\section{Eligibility criteria}

All studies focusing on the initial nonoperative management and comparing antibiotic treatment with appendectomy for acute nonperforated appendicitis in children were eligible for inclusion.

Commentaries, correspondence, editorials, letters, clinical guidelines, surveys, and case reports, as well as studies reporting nonoriginal data (systematic reviews, meta-analyses, narrative reviews) were excluded.

Studies addressing both adults and children or both perforated and nonperforated appendicitis and that did not report data from nonperforated disease and children separately were excluded. We also excluded all studies reporting data about immune-compromised children because of the potentially worse outcomes.

\section{Information sources}

A systematic search of the literature was performed in Medline via PubMed, Embase, Cochrane and Web of Science in May 2019.

\section{Search strategy}

Using Boolean operators AND and OR, we used all possible combination of the following search terms: "acute appendicitis, appendicitis, uncomplicated, noncomplicated, nonperforated, unperforated, conservative, antibiotic, nonoperative, child, children, infant, pediatric, adult". The search was limited to human subjects and children ( $0-18$ years), but without language or publication year restriction.

\section{Study selection}

The online systematic review management program Covidence (https://www.covidence.org/) was used to coordinate the screening and data collection process. Preliminary screening of all studies on title and abstracts was performed independently by two reviewers (SM and BA) with any disagreement resolved by the senior reviewer (JFS). After initial screening, full-text articles, meeting inclusion criteria, were selected for inclusion.

\section{Data collection process}

The data extraction was performed independently by two investigators (SM and BA) after reading the full-text publications. Both researchers extracted data into predefined protocols. The datasets were compared and any irregularities were corrected by a joint assessment among the authors. The final protocol specified 38 data items.

\section{Data items}

The main outcomes were the efficacy of nonoperative treatment and the complication rate of both treatment strategies. Efficacy was defined as no need of appendectomy during the initial hospital stay. A third outcome was appendectomy, in children who were discharged from the initial hospital stay, due to recurrent appendicitis or recurrent abdominal pain with normal appendix. Interval appendectomies due to surgeon's or parents' choice were also included.

We defined complications as conditions requiring general anesthesia after the initial treatment; perforated appendicitis or peritonitis after nonoperative treatment or postoperative complications requiring invasive intervention. Negative appendectomy was included as a complication in patients undergoing appendectomy as initial treatment.

Additional outcomes were hospital stay during the initial admission and total hospital stay, which included readmission during follow-up. 


\section{Summary measures}

The summary effects of each respective meta-analysis were presented in forest plots, rendering standardized mean differences (SMD) or odds ratio (OR) with $95 \%$ confidence intervals (CI), respectively.

\section{Results}

\section{Study selection}

The process to select articles is shown in the PRISMA flowchart in Fig. 1. The literature search yielded 2743 abstracts, which were screened. Forty-six articles were reviewed and 21 of these were included in the final analysis. The number of articles included in the separate quantitative analyses depended on availability of data for each outcome measure in each of the studies.

\section{Study characteristics}

The studies are briefly summarized in Table 1 [10-30]. Seven of the included studies were retrospective and 14 were prospective. Thirteen of the studies included comparative data, while 8 studies reported outcomes of nonoperative management without a control group. One of the comparative studies was based on administrative data from 45 hospitals in the United States [22]. Several of the comparative studies described selection based on patient or parent choice [17-20,25]. There was only one randomized controlled trial, which was a pilot trial. The pilot trial was designed to generate data to inform future randomized controlled trials [16]. In total, the studies reported 5727 patients treated nonoperatively. The studies had different inclusion and exclusion criteria with respect to age, symptom duration, and the presence of an appendicolith.
Fig. 1 Prisma flowchart showing the process of selecting articles for analysis

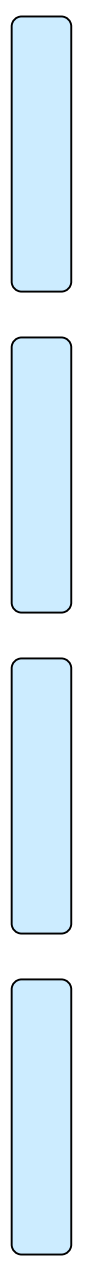


Table 1 Characteristics of included studies

\begin{tabular}{|c|c|c|c|c|c|}
\hline Study & $\begin{array}{l}\text { Year of } \\
\text { publication }\end{array}$ & Study design & Patients $n$, NOT & $\begin{array}{l}\text { Patients } n \text {, } \\
\text { appendectomy }\end{array}$ & Follow-up \\
\hline Kaneko et al. [1] & 2004 & Prospective, noncomparative & 22 & - & Median 36 months (24-45) \\
\hline Abes et al. [2] & 2007 & Retrospective, noncomparative & 16 & - & 12 months \\
\hline Armstrong et al. [3] & 2014 & Retrospective, comparative & 12 & 12 & Median 6.5 months \\
\hline Koike et al. [4] & 2014 & Retrospective, comparative & 130 & 114 & Mean 30.6 months \\
\hline Gorter et al. [5] & 2015 & Prospective, noncomparative & 25 & - & 8 weeks \\
\hline Steiner et al. [6] & 2015 & Prospective, noncomparative & 45 & - & 14 months \\
\hline Svensson et al. [7] & 2015 & Randomized controlled trial & 24 & 26 & At least 12 months \\
\hline Tanaka et al. [8] & 2015 & Prospective, comparative & 78 & 86 & Median 4.5 years \\
\hline Hartwich et al. [9] & 2016 & Prospective, comparative & 24 & 50 & Mean 14 months \\
\hline Mahida et al. [10] & 2016 & Prospective, comparative & 5 & 9 & 12 months \\
\hline Minneci et al. [11] & 2016 & Prospective comparative & 37 & 65 & Median 21 months \\
\hline Caruso et al. [12] & 2017 & Prospective, noncomparative & 197 & - & - \\
\hline Bachur et al. [13] & 2017 & Retrospective, comparative $^{a}$ & 4190 & 61522 & 12 months \\
\hline Steiner et al. [14] & 2017 & Prospective, noncomparative & 197 & - & 18 months \\
\hline Mudri et al. [15] & 2017 & Retrospective, comparative & 26 & 26 & 3 years \\
\hline Lee et al. [16] & 2018 & Prospective, comparative & 51 & 32 & Median 13 months \\
\hline Gorter et al. [17] & 2018 & Prospective, comparative & 25 & 19 & 25 months (16-36) \\
\hline Scott et al. [18] & 2018 & Retrospective, noncomparative & 50 & - & Median 305 days (125-375) \\
\hline Abbo et al. [19] & 2018 & Retrospective, noncomparative & 166 & - & Median 18.8 months (13-270) \\
\hline Steiner et al. [20] & 2018 & Prospective, noncomparative & 362 & - & 22 months $(6-43)$ \\
\hline Knaapen et al. [21] & 2019 & Prospective, noncomparative & 45 & - & 25 months $(16-36)$ \\
\hline
\end{tabular}

NOT nonoperative treatment, $S D$ standard deviation

${ }^{a}$ Data from an administrative database.

Fig. 2 Treatment efficacy. Sixteen studies were included in the analysis of treatment efficacy, defined as discharge without further complications

$\begin{array}{lrrrr}\text { Study } & \text { Cases } & \text { Total Proportions } & \mathbf{9 5 \%} \text { C.I. } \\ & & & & \\ \text { Koike, Y. 2014 } & 125 & 125 & 1.00[0.97 ; 1.00] \\ \text { Steiner, Z. 2018 } & 343 & 362 & 0.95[0.92 ; 0.97] \\ \text { Abbo, O. 2018 } & 162 & 166 & 0.98[0.94 ; 0.99] \\ \text { Tanaka, Y. 2015 } & 77 & 78 & 0.99[0.93 ; 1.00] \\ \text { Mudri, M. 2017 } & 26 & 26 & 1.00[0.87 ; 1.00] \\ \text { Gorter, R. R. 2015 } & 25 & 25 & 1.00[0.86 ; 1.00] \\ \text { Casuso, A. M. 2016 } & 115 & 197 & 0.58[0.51 ; 0.65] \\ \text { Minneci, P. C. 2015 } & 35 & 37 & 0.95[0.82 ; 0.99] \\ \text { Steiner, Z. 2015 } & 42 & 45 & 0.93[0.82 ; 0.99] \\ \text { Knaapen, M. 2018 } & 42 & 45 & 0.93[0.82 ; 0.99] \\ \text { Svensson, J. F. 2015 } & 22 & 24 & 0.92[0.73 ; 0.99] \\ \text { Abes, M. 2007 } & 15 & 16 & 0.94[0.70 ; 1.00] \\ \text { Lee, S. L. 2018 } & 35 & 51 & 0.69[0.54 ; 0.81] \\ \text { Hartwich, J. 2016 } & 21 & 24 & 0.88[0.68 ; 0.97] \\ \text { Armstrong, J. 2014 } & 11 & 12 & 0.92[0.62 ; 1.00] \\ \text { Machida, J. B. 2016 } & 3 & 5 & 0.60[0.15 ; 0.95] \\ & & & \end{array}$

Heterogeneity: $I^{2}=92 \%, \tau^{2}=0.0042, \chi_{15}^{2}=181.43(p<0.01)$

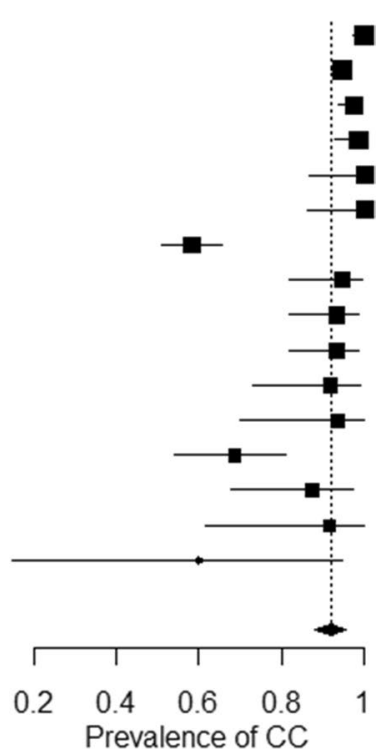




\section{Results of studies}

\section{Efficacy of nonoperative treatment}

Data from 16 studies were included in a meta-analysis to assess efficacy of nonoperative treatment (Fig. 2). Efficacy was defined in different ways in the included studies and nonoperative treatment was reported to be efficient in $92 \%$ [95\% CI $(88 ; 96)]$ of patients. Mahida et al. prospectively studied nonoperative treatment in patients with an appendicolith and reported that failure rate was $60 \%$. The study was stopped due to patient safety concerns [19]. Others also reported an increased failure rate in patients with an appendicolith $[25,27]$. Patients with an appendicolith were excluded from some studies, whereas the increased risk for failed treatment in the presence of an appendicolith could not be confirmed in other studies [16, 28].

\section{Complications of nonoperative treatment}

Eight studies were included in the comparative analysis of complications shown in Fig. 3. The overall complication rate was low in both groups. There were no differences with respect to complications between patients undergoing nonoperative treatment and appendectomy. Negative appendectomy, which was considered a complication in the appendectomy group, was reported in $0-6.2 \%$ of patients. A large retrospective review of administrative data from 45 pediatric hospitals in the United States showed that nonoperatively treated patients had more emergency department visits and hospitalizations compared with those managed with appendectomy [22].

\section{Recurrent appendicitis and long-term outcomes}

Except for $8 \%$ of patients undergoing appendectomy during initial hospital stay, meta-analysis, including 21 studies, showed that $16 \%$ (95\% CI 10; 22) of patients had undergone an appendectomy during follow-up (Fig. 4). The figures included patients who had undergone appendectomy due to recurrent appendicitis and patients with recurrent abdominal pain with histologically normal appendix. Svensson et al. reported that 7 of the 22 successfully nonoperatively treated patients underwent appendectomy after discharge from initial hospital stay. Only one of these patients had a microscopically confirmed recurrent acute appendicitis. The other patients underwent appendectomy due to recurrent abdominal pain $(n=5)$ or parental wish $(n=1)$ [16]. Abbo et al. reported that 2 of 19 patients had normal appendix [28]. We choose to also include patients who underwent interval appendectomy in the analysis as this required general anesthesia and could, therefore, be considered a failure.

\section{Odds ratio complications}

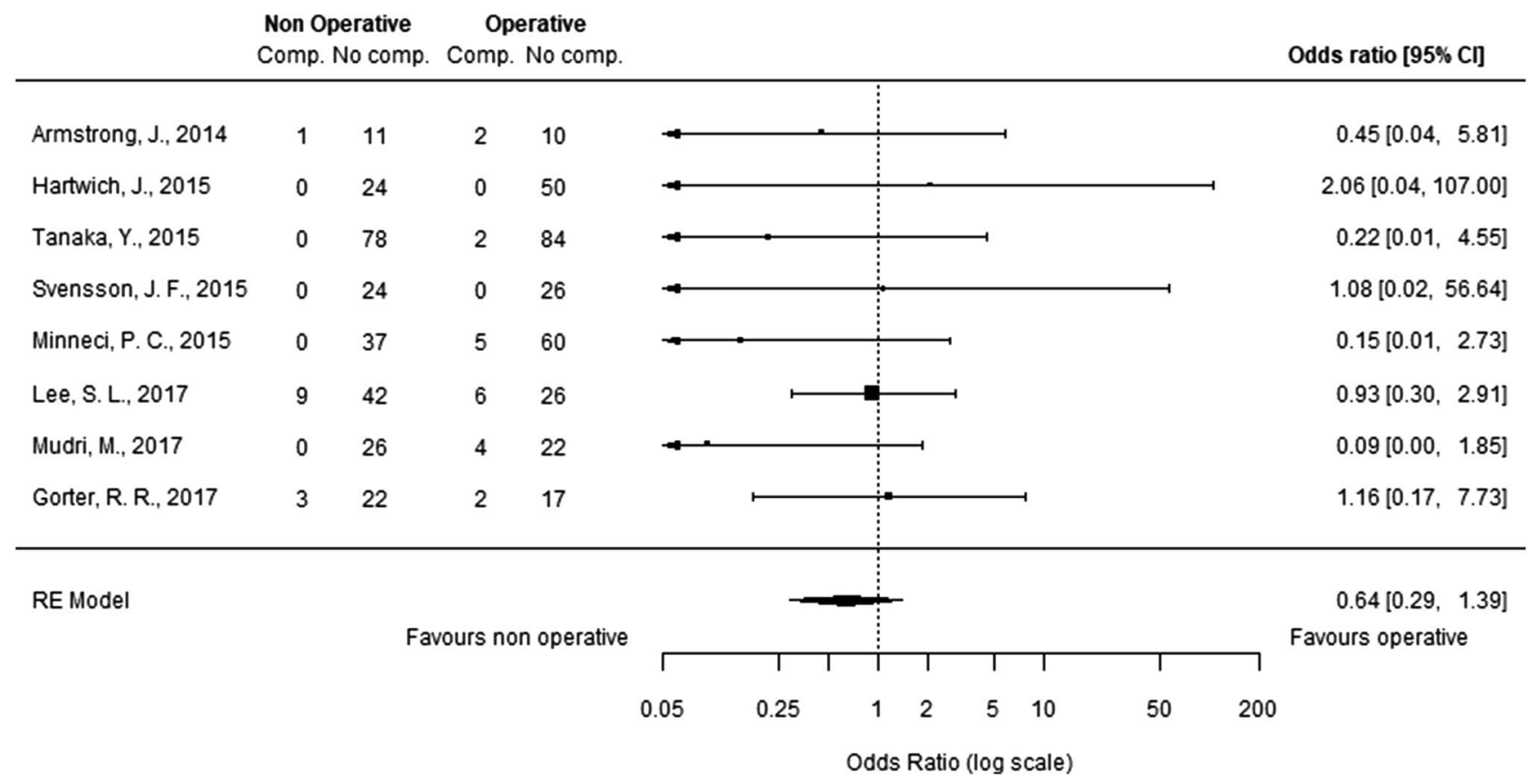

Fig. 3 Complications. Eight studies reported complications. Negative appendectomy was included among complications in the appendectomy group 


\section{Lenght of stay}

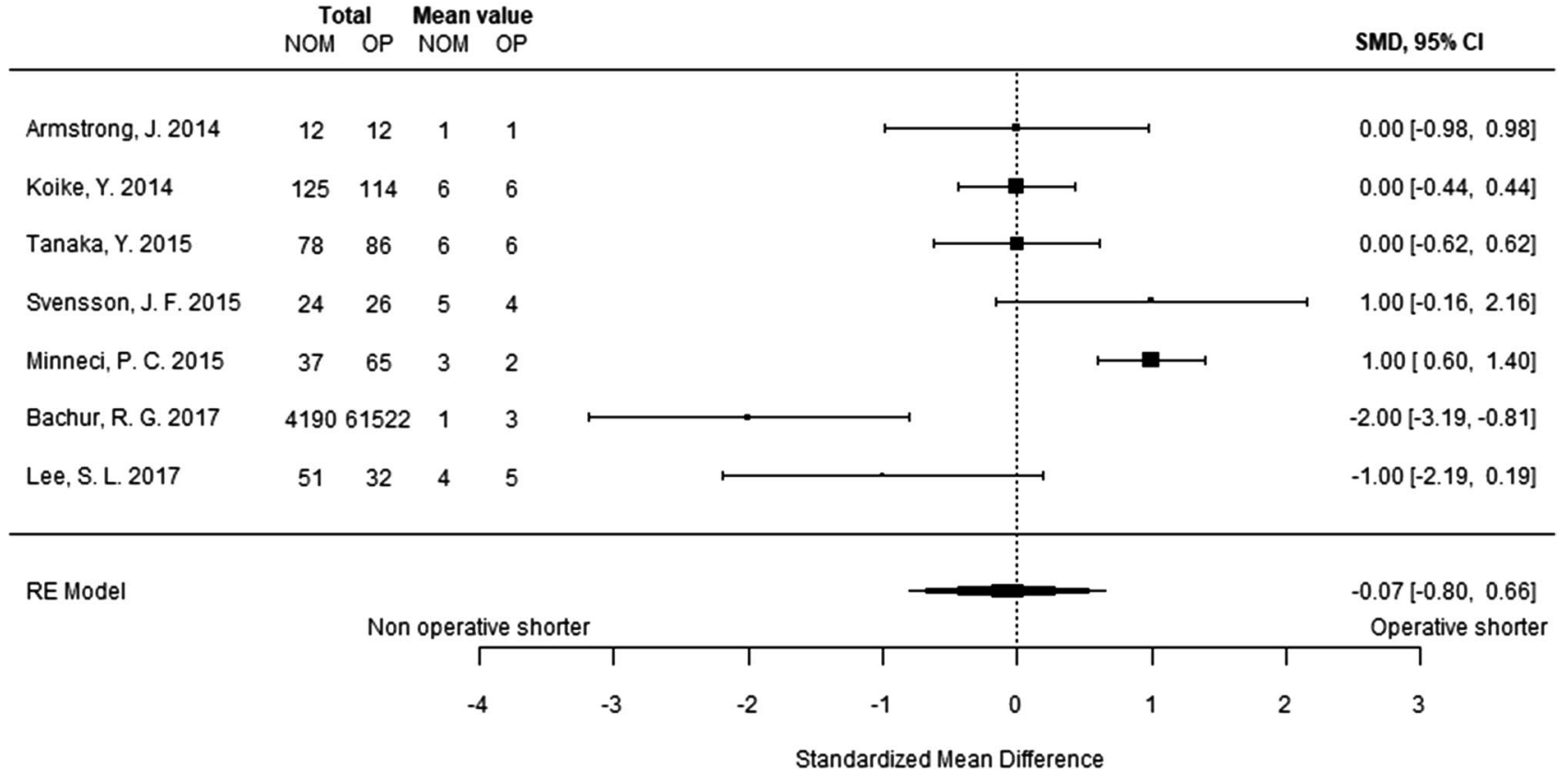

Fig. 4 Length of hospital stay. Length of initial hospital stay was compared based on data from seven studies

Fig. 5 Recurrent appendicitis. Twenty-one studies were included in the meta-analysis of recurrent appendicitis after discharge from the initial hospital stay. The analysis also included patients who underwent appendectomy due to recurrent abdominal pain with normal appendix, and interval appendectomies

\section{Study}

Bachur, R. G. 2017

Casuso, A. M. 2016

Steiner, Z. 2018

Steiner, Z. 2017

Abbo, O. 2018

Steiner, Z. 2015

Knaapen, M. 2018

Koike, Y. 2014

Scott, A. 2017

Tanaka, Y. 2015

Lee, S. L. 2018

Gorter, R. R. 2015

Hartwich, J. 2016

Minneci, P. C. 2015

Abes, M. 2007

Gorter, R. R. 2017

Svensson, J. F. 2015

Kaneko, K. 2004

Mudri, M. 2017

Armstrong, J. 2014

Machida, J. B. 2016

Random effects model

Heterogeneity: $I^{2}=97 \%, \tau^{2}=0.0160, \chi_{20}^{2}=642.84(p<0.01)$

$\begin{array}{rr}1032 & 4190 \\ 2 & 197 \\ 45 & 362 \\ 16 & 197 \\ 22 & 166 \\ 2 & 45 \\ 2 & 45 \\ 24 & 125 \\ 5 & 50 \\ 22 & 78 \\ 9 & 51 \\ 2 & 25 \\ 2 & 24 \\ 7 & 37 \\ 2 & 16 \\ 6 & 25 \\ 7 & 24 \\ 6 & 22 \\ 12 & 26 \\ 2 & 12 \\ 1 & 5\end{array}$

\section{Cases Total Proportions $\quad 95 \%$ C.I.}

$0.25[0.23 ; 0.26]$

$0.01[0.00 ; 0.04]$

$0.12[0.09 ; 0.16]$

$0.08[0.05 ; 0.13]$

$0.13[0.08 ; 0.19]$

$0.04[0.01 ; 0.15]$

$0.04[0.01 ; 0.15]$

$0.19[0.13 ; 0.27]$

$0.10[0.03 ; 0.22]$

$0.28[0.19 ; 0.40]$

$0.18[0.08 ; 0.31]$

$0.08[0.01 ; 0.26]$

$0.08[0.01 ; 0.27]$

$0.19[0.08 ; 0.35]$

$0.12[0.02 ; 0.38]$

$0.24[0.09 ; 0.45]$

$0.29[0.13 ; 0.51]$

$0.27[0.11 ; 0.50]$

$0.46[0.27 ; 0.67]$

$0.17[0.02 ; 0.48]$

$0.20[0.01 ; 0.72]$

$0.16[0.10 ; 0.22]$

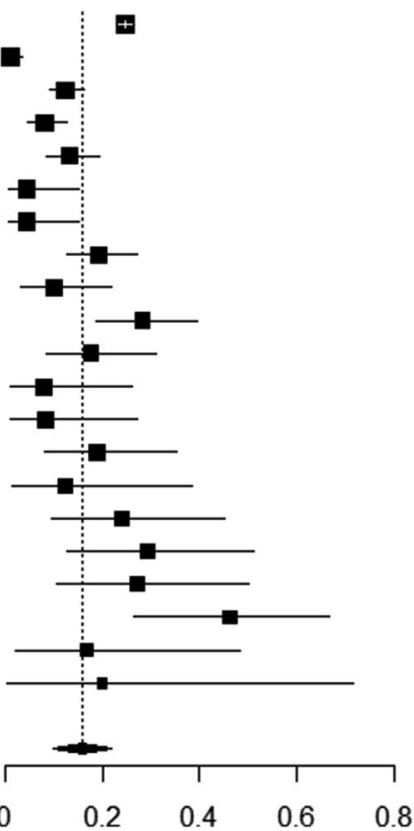

\section{Length of hospital stay}

The length of initial hospital stay was analyzed based on data from seven studies. There was no difference between the nonoperative treatment group and appendectomy group (Fig. 5).

\section{Length of total hospital stay}

Only two studies were included in analysis of total hospital stay, which included initial hospital stay and hospital stay at readmission. There was no difference between the groups (Fig. 6). 


\section{Total lenght of stay}

Total Mean value

SMD, $95 \% \mathrm{Cl}$

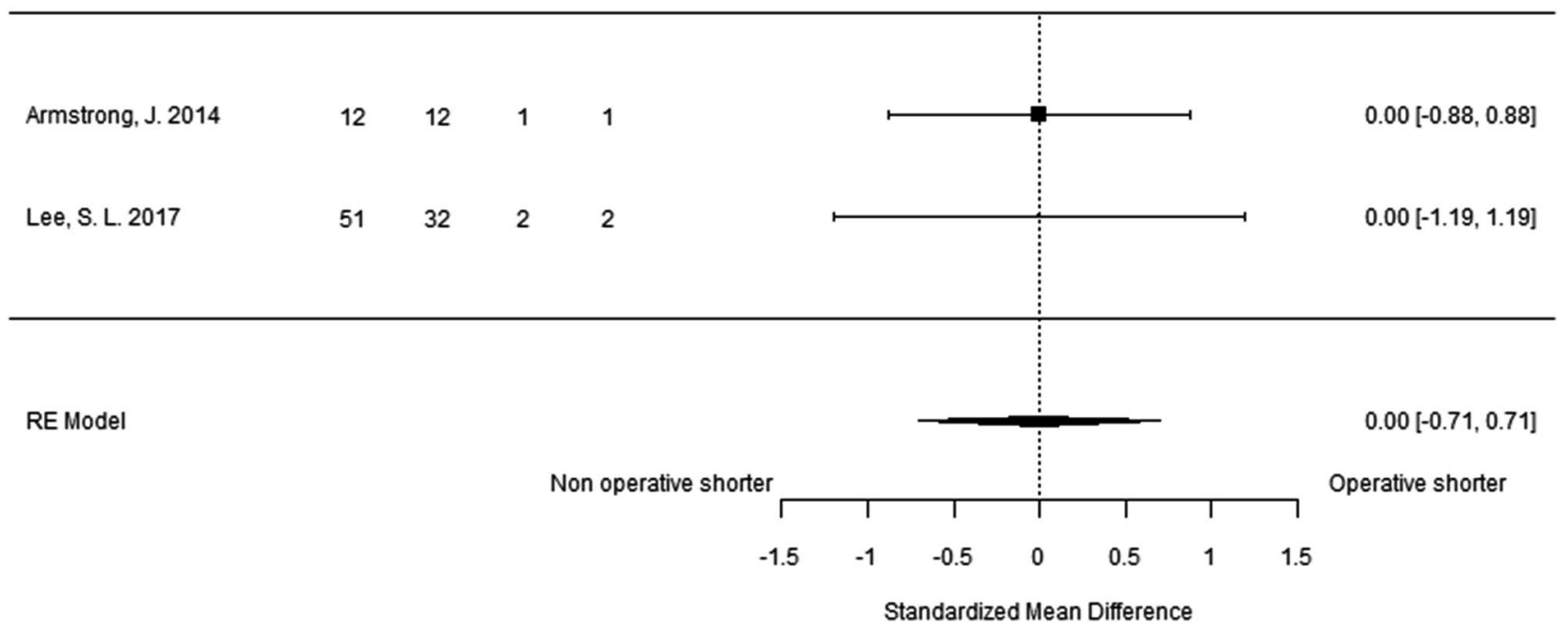

Fig. 6 Total length of hospital stays. This included the initial hospital stay and hospital stay during readmissions

\section{Discussion}

\section{Summary of evidence}

Nonoperative treatment of acute appendicitis in children is safe, with a complication rate comparable to that in patients undergoing appendectomy. The treatment is successful, defined as resolution of symptoms and discharge from initial hospital stay without appendectomy, in $92 \%$ of the patients. After discharge, another $16 \%$ of patients undergo appendectomy due to recurrent acute appendicitis or recurrent abdominal pain with normal appendix. The hospital stay is similar in patients treated nonoperatively and with appendectomy.

Kessler et al., in a previous systematic review and metaanalysis, including five comparative studies, presented data in favor of appendectomy with respect to efficacy of nonoperative treatment and readmission rate, while complications were similar in both groups. The conclusion from this study was that appendectomy should be considered the treatment of choice for management of nonperforated appendicitis in children [31]. Georgiou et al. used slightly different inclusion criteria in another recent systematic review and metaanalysis. They included comparative studies, but also studies reporting outcomes after nonoperative treatment without a control group. Nonoperative treatment was reported to be successful in $97 \%$ of the children. The hospital stay was shorter after appendectomy. Complication rate was similar in both groups. At last follow-up, $82 \%$ of patients treated nonoperatively had not undergone appendectomy, compared to $76 \%$ of patients in the present study. Fourteen percent of the patients underwent appendectomy for recurrent appendicitis [32].

Kessler et al. compared nonoperatively treated patients with and without appendicolith in a sub-analysis. No statistically significant differences were found with respect to complications and efficacy, but readmission rate was lower in those without an appendicolith. Excluding patients with appendicolith improved efficacy in the total group of nonoperatively treated patients [31].

Several studies reported on interval appendectomies done due to parent's request $[16,18,26]$ and a higher rate of emergency department visits for complaints of abdominal pain in patients who underwent nonoperative treatment [22]. One issue that may need to be further addressed is the quality of life and parent/patient satisfaction with nonoperative treatment. Four studies compared quality of life through questionnaires given to patients and their parents. Tanaka et al. showed that 1 year after initial treatment, patients who underwent operative treatment were much more satisfied than patients who underwent nonoperative treatment [17], while Hartwich et al. found experiences in favour of nonoperative treatment at 30 days [18]. Other studies found no differences between operative and nonoperative treatments [20, 25]. Minneci et al. stressed the importance of engaging families in the decision, allowing therapy to be aligned with their preferences and real-life concerns, such as cultural values and distance from the hospital [20]. 


\section{Limitations}

One main limitation of this meta-analysis was the heterogenous design of included studies. Inclusion and exclusion criteria, age, symptom duration, and the presence of appendicolith, were different in the included studies. The protocol for treatment with antibiotics, in the nonoperative treatment group, varied between the studies. Several studies were of low quality, with considerable risk for selection bias. There was only one randomized controlled pilot trial available.

Several of the comparative studies used a parent or patient choice design. We appreciate that the opinion of patients and parents is crucial for nonoperative treatment for children with acute appendicitis being a viable treatment option. The balance between optimizing recruitment and achieving acceptability of a randomized controlled trial to participants is a challenge for researchers. To have high external validity, the proportion of the study population of interest who are actually recruited into the randomized controlled trial should be high and representative. But, it is also important to have high internal validity to avoid selection bias, and this is best achieved with a randomized controlled trial. Due to the lack of randomization, and the likelihood of bias toward the less severely ill patients choosing antibiotic treatment, we are not able to assume that the group undergoing appendectomy are in a similar clinical condition using the parent or patient choice design. Only a true randomized controlled trial will minimize the likelihood of these differences influencing trial results. [33] Another limitation to this meta-analysis is the limited data on long-term follow-up. In children, there are no available long-term data. In adults, a recent 5-year follow-up of the APPAC trial showed that $27 \%$ of patients had undergone appendectomy at 1 year and $39 \%$ at 5 years, indicating that recurrences occur also in long term [34].

\section{Future perspectives}

Consequences that are related to antibiotic resistance should be taken into account when appendicitis is treated nonoperatively, but this issue has not been addressed in the present studies. Interestingly, two recent trial study protocols describe one trial planning to compare antibiotics with placebo for nonperforated appendicitis in adults and another trial designed to investigate microbiota and effects of antimicrobial treatment of appendicitis in adults. [35, 36]

\section{Conclusions}

This systematic review and meta-analysis show that nonoperative treatment of nonperforated acute appendicitis in children is safe and efficient. However, large randomized controlled trials are necessary to compare outcomes with appendectomy. Currently, the authors only treat nonperforated appendicitis with antibiotics as part of an ongoing randomized controlled trial. Patients not included in the trial undergo appendectomy.

Acknowledgements Open access funding provided by Karolinska Institute.

Funding Grant support was received by the Swedish Research Council (2016-00248), HKH Kronprinsessan Lovisas Förening för Barnasjukvård and Sällskapet Barnavård. The funders had no role in study design, data collection and analysis, decision to publish, or preparation of the manuscript.

\section{Compliance with ethical standards}

Conflict of interest The authors declare no conflict of interest.

Ethical approval This was a systematic review and meta-analysis and does not contain any studies with human participants performed by any of the authors.

Open Access This article is licensed under a Creative Commons Attribution 4.0 International License, which permits use, sharing, adaptation, distribution and reproduction in any medium or format, as long as you give appropriate credit to the original author(s) and the source, provide a link to the Creative Commons licence, and indicate if changes were made. The images or other third party material in this article are included in the article's Creative Commons licence, unless indicated otherwise in a credit line to the material. If material is not included in the article's Creative Commons licence and your intended use is not permitted by statutory regulation or exceeds the permitted use, you will need to obtain permission directly from the copyright holder. To view a copy of this licence, visit http://creativecommons.org/licenses/by/4.0/.

\section{References}

1. Addiss DG, Schaffer N, Fowler BS, Tauxe RV (1990) The epidemiology of appendicitis and appendectomy in the United States. Am J Epidemiol 132:910-925

2. Andersson RE (2007) The natural history and traditional management of appendicitis revisited: spontaneous resolution and predominance of prehospital perforations imply that a correct diagnosis is more important than an early diagnosis. World J Surg 31:86-92

3. You H, Sweeney A, Cooper ML, VonPapen M, Innes J (2019) The management of diverticulitis:a review of the guidelines. Med J Aust. https://doi.org/10.5694/mja2.50276

4. Svensson JF, Hall NJ, Eaton S, Pierro A, Wester T (2012) A review of conservative treatment of acute appendicitis. Eur J Pediatr Surg 22:185-94

5. Bollinger RR, Barbas AS, Bush EL, Lin SS, Parker W (2007) Biofilms in the large bowel suggest an apparent function of the human vermiform appendix. J Theor Biol 249:826-831

6. De Coppi P, Pozzobon M, Piccoli M, Gazzola MV, Boldrin L, Slanzi E, Destro R, Zanesco L, Zanon GF, Gamba P (2006) Isolation of mesenchymal stem cells from human vermiform appendix. J Surg Res 135(85):91

7. Rawolle T, Reismann M, Minderjahn MI, Bassir C, Hauptmann K, Rothe K, Reismann J (2019) Sonographic differentiation 
of complicated from uncomplicated appendicitis. Br J Radiol 92(1099):20190102. https://doi.org/10.1259/bjr.20190102

8. Rubér M, Andersson M, Petersson BF, Olaison G, Andersson RE, Ekerfelt C (2010) Systemic Th17-like cytokine pattern in gangrenous appendicitis but not in phlegmounous appendicitis. Surgery 147:366-372

9. Lindestam U, Almström M, Jacks J, Malmquist P, Lönnqvist PA, Jensen BL, Carlström M, Krmar RT, Svensson JF, Norberg Å, Fläring U (2019) Low plasma sodium concentration predicts perforated acute appendicitis in children: a prospective diagnostic accuracy study. Eur J Pediatr Surg. https://doi. org/10.1055/s-0039-1687870

10. Kaneko K, Tsuda M (2004) Ultrasound-based decision making in the treatrment of acute appendicitis in children. J Pediatr Surg 39:1316-1320

11. Abes M, Petik B, Kazil S (2007) Nonoperative treatment of acute ppendicitis in children. J Pediatr Surg 42:1439-1442

12. Armstrong J, Merritt N, Jones S, Scott L, Bütter A (2014) Nonoperative management of early, acute appendicitis in children: is it safe and effective. J Pediatr Surg 49:782-785

13. Koike Y, Uchida K, Matsushita K, Otake K, Nakazawa M, Inoue M, Kusunoki T, Tsukamoto Y (2014) Intraluminal appendiceal fluid is a predictive factor for recurrent appendicitis after initial successful non-operative management of uncomplicated appendicitis in pediatric patients. J Pediatr Surg 49:1116-1121

14. Gorter RR, van der Lee JH, Cense HA, Kneepkens CMF, Wijnen MHWA, Hof KH, Offringa M, Heij HA (2015) Initial antibiotic treatment for acute simple appendicitis in children is safe: shortterm results from a multicenter, prospective cohort study. Surgery 157:916-923

15. Steiner Z, Buklan G, Stackievicz Gutermacher M, Eeez I (2015) Arole for conservative antibiotic treatment in eraly appendicitis in children. J Pediatr Surg 50:1566-1568

16. Svensson JF, Patkova B, Almström M, Naji H, Hall NJ, Eaton S, Pierro A, Wester T (2015) Nonoperative treatment with antibiotics versus surgery for acute nonperforated appendicitis in children. Ann Surg 261:67-71

17. Tanaka Y, Uchida H, Kawashima H, Fujiogi M, Takazawa S, Deie K, Amano H (2015) Long-term outcomes of operative versus nonoperative treatment for uncomplicated appendicitis. J Pediatr Surg 50:1893-1897

18. Hartwich J, Luks FI, Watson-Smith D, Kurkchubasche AG, Muratore CS, Wills HE, Tracy TF (2016) Nonoperative treatment of acute appendicitis in children: a feasibility study. J Pediatr Surg 51:111-116

19. Mahida JB, Lodwick DL, Nacion KM, Sulkowski JP, Leonhart KL, Cooper JN, Ambeba EJ, Deans KJ, Minneci PC (2016) High failure rate of nonoperative management of acute appendicitis with an appendicolith in children. J Pediatr Surg 51:908-911

20. Minneci PC, Mahida JB, Lodwick D, Sulkowski JP, Nacion KM, Cooper JN, Ambeba EJ, Moss RL, Deans KJ (2016) Effectivenss of patient choice in nonoperative vs surgical management of pediatric uncomplicated acute appendicitis. JAMA Surg 151:408-415

21. Caruso AM, Pane A, Garau R, Atzori P, Podda M, Casuccio A, Mascia L (2017) Acute appendicitis in children: not only surgical treatment. J Pediatr Surg 52:444-448

22. Bachur RG, Lipsett SC, Monuteaux MC (2017) Outcomes of nonoperative management of uncomplicated appendicitis. Pediatrics. https://doi.org/10.1542/peds.2017-0048

23. Steiner Z, Buklan G, Stackievicz R, Gutermacher M, Litmanovitz I, Golani G, Arnon S (2017) Conservative treatment in uncomplicated acute appendicitis reassessment of practice safety. Eur J Pediatr 176:521-527
24. Mudri M, Coriolano K, Bütter A (2017) Cost analysis of nonoperative managemrnt of acute appendicitis in children. J Pediatr Surg 52:791-794

25. Lee SL, Spence L, Mock K, Wu JX, Yan H, De Ugarte DA (2018) Expanding the inclusion criteria for non-operative management og uncomplicated appendicitis: outcomes and cost. J Pediatr Surg 53:42-47

26. Gorter RR, van der Lee JH, Heijsters FACJ, Cense HA, Bakx R, Kneepkens CMF, Wijnen MH, van der Steeg AFW, Hof KH, Offringa M, Heij HA (2018) Outcome of initially nonoperative treatment for acute simple appendicitis in children. J Pediatr Surg 53:1849-1854

27. Scott A, Lee SL, DeUgarte DA, Shew SB, Dunn JCY, Shekherdimian S (2018) Nonoperative management of appendicitis. Clin Pediatr 57:200-204

28. Abbo O, Trabiano C, Pinnagoda K, Kaci AA, Carfagna L, Mouttalib S, Combelles S, Vial J, Galinier P (2018) Non-operative management for uncomplicated appendicitis: an optio to consider. Eur J Pediatr Surg 28:18-21

29. Steiner Z, Buklan G, Gutermacher M, Litmanovitz I, Landa $\mathrm{T}$, Arnon S (2018) Conservative antibiotic treatment for acute uncomplicated appendicitis is feasible. Peditr Surg Int 34:283-288

30. Knaapen M, van der Lee JH, Heij HA, van Heurn ELW, Bakx $\mathrm{R}$, Gorter RR (2019) Clinical recovery in children with uncomplicated appendicitis undergoing non-operative treatment: secondary analysis of a prospective cohort study. Eur J Pediatr Surg 178:235-242

31. Kessler U, Mosbahi S, Walker B, Hau EM, Cotton M, Peiry B, Berger S, Egger B (2017) Conservative treatment versus surgery for uncomplicated appendicitis in childre: a systematic review and meta-analysis. Arch Dis Child 102:1118-1124

32. Georgiou R, Eaton S, Stanton M, Pierro A, Hall NJ (2017) Efficacy and safety of nonoperative treatment for acute appendicitis: a meta-analysis. Pediatrics 139(3):e20163003. https://doi. org/10.1542/peds.2016-3003

33. Svensson JF, Patkova B, Almström M, Naji H, Wester T, Hall NJ, Eaton S, Pierro A (2017) Design of studies for antibiotic treatment of acute appendicitis in children: in support of RCTs. Ann Surg 266(1):6-7. https://doi.org/10.1097/SLA.000000000001291

34. Salminen P, Tuominen R, Paajanen H, Rautio T, Nordström P, Aarnio M, Rantanen T, Hurme S, Mecklin JP, Sand J, Virtanen J, Jartti A, Grönroos JM (2018) Five-year follow up of antibiotic therapy for uncomlicated acute appendicitis in the APPAC randomized clinical trial. JAMA 320:1259-1265

35. Sippola S, Grönroos J, Sallinen V, Rautio T, Nordström P, Rantanen T, Hurme S, Leppäniemi A, Meriläinen S, Laukkarinen J, Savolainen H, Virtanen J, Salminen P (2018) A randomised placebo-controlled double-blind multicentre trial comparing antibiotic therapy with placebo in the treatment of uncomplicated acute appendicitis: APPAC III trial study protocol. BMJ Open 8(11):e23623. https://doi.org/10.1136/bmjopen-2018-023623

36. Vanhatalo S, Munukka E, Sippola S, Jalkanen S, Gröroos J, Marttila H, Eerola E, Hurme S, Hakanen AJ, Salminen P, APPAC collaborative Study Group (2019) Prospective multicentre cohort trial on acute appendicitis and microbiota, aetiology and effects of antimicrobial treatment: study protocol for the MAPPAC (Microbiology Appendicitis Acuta). BMJ Open 9(9):e031137. https:// doi.org/10.1136/bmjopen-2019-031137

Publisher's Note Springer Nature remains neutral with regard to jurisdictional claims in published maps and institutional affiliations. 